\title{
LA GLOBALIZACIÓN CAPITALISTA Y EL LUGAR EPISTÉMICO DE LA EDUCACIÓN POPULAR EN AMÉRICA LATINA Entrevista con Marco Raúl Mejía
}

\begin{abstract}
MARCO RAÚL MEJíA es licenciado en Filosofía y Letras de la Pontificia Universidad Javeriana de Bogotá (Colombia) y doctor del Proyecto Interdisciplinario de Investigaciones Educativas en Chile (PIIE). Autor de importantes libros y textos sobre educación popular en América Latina, como Globalizaciones y educaciones, Educación popular en el siglo XXI y Sistematización. Marco Raúl Mejía también es educador popular en los proyectos Planeta Paz y la Expedición Pedagógica Nacional de Colombia.
\end{abstract}

La educación popular ha sido promovida en América Latina desde la segunda mitad del siglo $\mathrm{XX}$, planteando un nuevo discurso pedagógico que emerge en las décadas de 1950 y 1960 como respuesta a la modernidad y a una educación hegemónica, con las contradicciones subyacentes al desarrollo del capitalismo en la región. Los procesos de urbanización, las distorsiones ciudad/campo y los dilemas materiales y culturales de la masificación de las sociedades nacionales, generaron difusas narrativas y contra-narrativas respecto a la marginalización, la precariedad de los mecanismos de cohesión social, la movilización popular, entre otros aspectos. El eje de los proyectos de educación popular, incluye justamente la explicitación de las asimetrías sociales y los contextos de exclusión a través de una crítica de lo popular, a la luz de las estructuras de producción y reproducción de consciencia e ideología. La dialéctica de nuestra situación periférica, leída desde la lupa de la educación popular, queda evidenciada en este problema.

Como proyecto de emancipación social construido en las reivindicaciones políticas desde abajo, la educación popular es parte del laberinto político e ideológico de nuestra modernidad, cuestionando la realidad y las ideologías existentes a través del diálogo, la crítica y la reflexión. Sin embargo, la actual coyuntura en Latinoamérica nos lleva a pensar acerca de los retos y las fracturas de los procesos de democratización social en la región. Especialmente desde 2016, los gobiernos progresistas de izquierda han sufrido reveses significativos: podemos pensar, en ese sentido, en los desgastes institucionales (Chile y Bolivia), en las derrocadas (Argentina, Brasil, Perú y Paraguay) o en las encrucijadas institucionales e ideológicas (Venezuela). La coyuntura de la pink tide o vuelta hacia la izquierda, a ideas más progresistas en los años 2000, ha generado cambios drásticos en la región, así como la nueva racionalidad neoliberal y el ascenso de los populismos y del ultranacionalismo han representado un tournant histórico significativo para los horizontes de acción 
colectiva. Es cierto que, si hay un ocaso del ciclo histórico de gobiernos de izquierda (a pesar del contenido historicista implícito en la aserción), el lugar de los movimientos sociales y de la educación popular - debe ser repensado a la luz de esos procesos sociales más amplios.

Creemos que todos estos argumentos dialogan con las preocupaciones de Marco Raúl Mejía, en la entrevista amablemente concedida a Cadernos CIMEAC. La pregunta por el territorio de la educación popular en los procesos de democratización de América Latina implica una investigación aún más profunda acerca de sus contenidos orientadores a la luz de una crítica de la globalización capitalista y, en ese sentido, el "lugar epistémico" de la educación popular latinoamericana, a partir de una mirada desde el Sur global, como parte fundamental para la reflexión crítica. Para Mejía, así como para una larga corriente de los estudios postcoloniales y de las teorías de la descolonización, el Sur es un referencial simbólico y material fundamental. Más que una coordenada geográfica, se trata de un lugar epistémico para dar consistencia a lo diverso y a los regímenes de opresión y silenciamiento que emergen de la estructura asimétrica de los procesos de modernización.

En el contexto de la aceleración de las transformaciones técnicas y de la afirmación de la pluralidad de las identidades sociales, la reflexión contemporánea sobre educación popular también tiene que ver con la ascensión de lo inmaterial, el problema de la interculturalidad y la formulación de nuevas epistemologías desde nuestra realidad. Como práctica transformadora y matriz de nuevas subjetividades, la educación popular plantea el problema de lo común y la apropiación de saberes y bienes culturales desde un horizonte políticamente saturado por las fracturas de nuestra democratización. En ese sentido, además de la multiplicidad de experiencias en educación popular en el continente, así como el acumulado de saberes y problemas, se plantea un "campo prácticoteórico" en constitución permanente "para dar respuesta a los tiempos que corren".

Danilo Seithi Kato (UFTM)

Felipe Ziotti Narita (USP / Unesp)

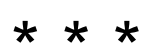

CIMEAC: Los proyectos de educación popular en América Latina han sido fundamentales para la consolidación de la sociedad civil desde los años 1980 y 1990. ¿Cómo usted analiza ese proceso teniendo en cuenta la democratización política de las sociedades latinoamericanas en aquella coyuntura? ¿Es posible decir que la educación popular desempeñó una función importante para la construcción democrática en el continente?

Marco Raúl Mejía: Creo que éste representa uno de los hitos más importantes en la consolidación de la educación popular en América Latina, pero a su vez 
representó uno de los momentos más paradójicos, porque después de este período de fin de las dictaduras muchas de las personas que habían trabajado en la educación popular y algunas de las agencias de cooperación que habían ayudado a su financiación, plantearon que era el fin de la educación popular, ya que su vigencia estaba atada al proceso de consolidación de las democracias. Ese momento abre un gran debate sobre cuál es el lugar en las democracias que se inauguraban de la propuesta de la educación popular, y en ese período aparece un gran debate sobre la manera cómo el tránsito debía ser aprovechado para organizar una fundamentación de ella que la colocara de cara a las nuevas realidades de una globalización capitalista y neoliberal en marcha. Es un momento en el que, además de las posiciones de su fin aparecen propuestas como la refundamentación, la reconfiguración, la rearticulación a los proyectos populares y otras palabras que intentaban dar cuenta de cómo vivir ese tránsito. Ese momento histórico abre un debate profundo sobre los contenidos de la educación popular, su ligazón al proyecto freireano o al proyecto marxista de transformación de las estructuras y se iniciaban los primeros balances sobre lo que había sido el acompañamiento de ella y su articulación a los procesos revolucionarios en Centroamérica, y se introducen discusiones sobre su pedagogía, su ética, sus relaciones con el marxismo clásico y se inicia un período profundo de elaboración, el cual puede ser visto en los debates generados en la revista La Piragua (CEAAL), y en los procesos de movimientos sociales que acompañaron ese tránsito a la democracia. Pudiéramos afirmar que esas resistencias a la dictadura para refundar la democracia, se vuelve central a las discusiones de la educación popular, siendo éste un período difícil, por las descalificaciones que se dieron entre las diferentes posiciones, en cuanto el discurso sobre el reformismo, la socialdemocracia, la revolución, el intelectualismo, el populismo, impregnó el debate de ese período sobre la educación popular. Este debate permitió decantar una educación popular que desde variadas concepciones y posiciones acompañó el surgimiento a lo largo del continente de lo que sería el ciclo de los gobiernos progresistas (Venezuela, Ecuador, Bolivia, Brasil, Chile, Uruguay, Argentina), que tuvo como correlato el que muchos movimientos apoyaran estos procesos generando una dinámica en la cual muchos de los educadores populares fueran a ocupar puestos gubernamentales, generándose un nuevo ámbito de actuación de los educadores populares que no había sido ocupado todavía a lo largo de sus desarrollos en la segunda mitad del siglo XX. A su vez, se generó toda una discusión sobre la manera cómo estos gobiernos cooptaron los movimientos sociales y muchos de ellos fueron subsumidos en sus plataformas programáticas, y en otros lugares se generó la discusión sobre la manera cómo era necesario construir lo político de lo social que permitiera diferenciar lo político partidario. Estos debates permitieron una elaboración que avanzó sobre la manera cómo la política también comenzaba a tener unas particularidades desde los contextos latinoamericanos, diferentes a lo que sería el pensamiento clásico 
ortodoxo del marxismo como pensamiento crítico por excelencia de Occidente. Este debate no acaba de concluirse, pero ha sido de una vitalidad que ha venido a ser como una savia de la educación popular, en cuanto le ha permitido diferenciarse y a la vez decantar su propuesta como una propuesta para toda la sociedad, viéndose obligado a reorganizar su pensamiento no solo a la luz de los fenómenos de la tercera y la cuarta revolución productiva, sino que las crisis de los gobiernos progresistas colocaron nuevos asuntos centrales a un ejercicio que el Padre Cardenal, de Nicaragua, llamó "lo ético como exigencia de la política", en donde insistía en que no bastaba cambiar la sociedad o tener los sueños de hacerlo si no cambiábamos la vida y la manera cómo los ideales de ese proyecto eran encarnados en lo cotidiano y en el quehacer de personas, movimientos e instituciones.

CIMEAC: La reconfiguración de la sociedad de clases en el contexto del capitalismo cognitivo y de la ascensión de lo inmaterial ha producido cambios importantes en el saber y en sus formas de circulación y apropiación. ¿Cómo usted analiza la educación popular a la luz de eso proceso social más amplio?

Marco Raúl Mejía: Igual que cualquier actividad humana de este tiempo, la educación popular es tocada por un mundo que en sus últimos 40 años ha vivido dos revoluciones productivas (microelectrónica y la del trabajo inmaterial e inteligencia artificial), cuando se necesitaron 300 años para las dos primeras (la del vapor y la de la electricidad). En esa perspectiva, la educación popular no solo se ve impelida a pensar el mundo local sino la emergencia de un mundo glocal, caracterizado por profundas transformaciones en las cuales los asuntos de los cuales se ocupa ella también se transforman a la luz de un nuevo fenómeno, en el cual la ciencia se convierte en fuerza productiva fundamental con las consecuencias de la necesidad de reelaborar esa teoría sobre el capital y la manera cómo él se daba en las particularidades de nuestra formación social. Y la particularidad de este tiempo, en el sentido de la pregunta, es que esa ciencia al convertirse en fuerza productiva fundamental por la espectacularidad de los cambios tecnológicos, hace que por momentos olvidemos que ella es resultante del trabajo humano, aquello que Marx había llamado "fuerza científica objetivada", lo cual exige una relectura de ese pensamiento crítico para traerla a nuestras realidades y a la vez hacer un planteamiento sobre la manera cómo el capital se apropia de esa ciencia y la coloca al servicio de éste. Por eso, una relectura de los Grundisse va a ser muy importante para el pensamiento crítico de este tiempo, al intentar explicar las nuevas maneras de las clases, en donde las nuevas fuerzas productivas sociales son producidas como ciencia, pero también en la organización de la praxis social cotidiana. Este tiempo se vuelve maravilloso para la educación popular, porque la encuentra en un momento para ella de consolidación y de tener que explicarse en los fenómenos del capital global y la manera cómo en su formación social adquiere concreción esa realidad 
desde las particularidades nuestras, de lo cual ya nos había enseñado Mariátegui cuando hablaba de la sociedad indoamericana, lo cual le valió un regaño del Komintern en la década del 30 del siglo pasado, o de la manera cómo pensadores como el boliviano Zabaleta habla de las "formaciones sociales abigarradas", mostrando la convivencia de esas múltiples formas del capital y que se hacen específicas y particulares en la singularidad de nuestra formación social. Esta consolidación de la educación popular como un proyecto educativo para toda la sociedad y todas las formas de educación, le permite decantar en esa lectura crítica un nuevo horizonte teórico, y lo hace recordando cómo el capitalismo occidental ha sido constituido desde unas homogeneizaciones que les ha permitido construir un relato único del mundo, bien sea en su versión liberal o en la más crítica emancipadora, que ha dado forma a explicaciones universales que comienzan a discernirse en las nuevas condiciones del mundo y las particularidades de nuestros contextos. La primera homogeneización sobre la cual se produce el capital es la biótica, la cual, al construir el predominio de lo humano sobre la naturaleza y un sistema de objetivación de ella, produce un antropocentrismo que va a permitir una visión de exterioridad de la naturaleza. En el horizonte de estos tiempos, en el pensamiento latinoamericano ha emergido con fuerza propia la mirada sobre el Buen Vivir / Vivir Bien, en el cual se da cuenta de un mundo integral y una unidad a ser recuperada en cualquier proyecto que se intente construir. La segunda homogeneización, la cultural, ha permitido construir un relato de la modernidad centrado sobre la idea de progreso con un conocimiento universal de base eurocéntrico y norteamericano, el cual se constituye en el relato único para explicar el mundo, que a su vez permite esa organización del mundo entre desarrollo y subdesarrollo, moderno y premoderno, capitalista-precapitalista. A esta mirada desde los sectores críticos y desde la educación popular se ha venido haciendo visible la manera cómo emerge un Sur, que da lugar a hacer visible la diversidad, la diferencia, en un mundo donde las desigualdades son construidas por su negación y por la incapacidad de construir mundos pluriversos. La tercera homogeneización, en marcha, es la educativa, e intenta cerrar el ciclo de un mundo organizado a través de patrones universales, que son establecidos a partir del STEM (acrónimo de Science, Technology, Engineering, Mathematics o ciencia, tecnología, ingeniería y matemáticas por sus siglas en inglés, así como la lectura y escritura de ellas), para lo cual se construye unos estándares y competencias de referencia universal para vivir en este mundo productivo. Allí la educación popular, a medida que consolida su acumulado, desarrolla propuestas que permiten recuperar la diversidad, trabajando un proyecto integral de lo humano desde las capacidades y las habilidades y desarrolla metodologías que hagan posible la expresión de esa diversidad. 
CIMEAC: En un artículo publicado en 2007 en la revista Pasos, usted define la educación popular como una práctica de "empoderamiento que permita a los grupos segregados y desiguales construir un proyecto de sociedad". En América Latina, a la luz de la modernización capitalista de los últimos 150 años, indicadores crónicos de desigualdad y asimetrías sociales constituyen contextos de exclusión y deterioro de lo social. ¿Hay un conjunto estructural de problemas en el horizonte de la educación popular latinoamericana capaz de tematizarla como un campo unificado de prácticas e investigaciones?

Marco Raúl Mejía: En coherencia con las respuestas a las dos preguntas anteriores, podemos afirmar que hoy la educación popular es una propuesta educativa para toda la sociedad y en sus diferentes ámbitos, con un acumulado que permite construir un campo práctico-teórico que además, por la manera como se ha desarrollado, está en constitución permanente para dar respuesta a los tiempos que corren. En ese sentido, pudiéramos decir que ese acumulado la dota de: una historia, una conceptualización decantada, un lugar epistémico, una propuesta pedagógica, y unas nuevas metodologías de investigación. Su historia, a medida que se comienza a profundizar, se confunde con la manera cómo el proyecto de la Revolución francesa habló de educación popular como la pública, que debía darse a quienes no habían tenido acceso al conocimiento y al saber como factor básico de democratización. En ese sentido, esa versión de ella, que llega a las nacientes repúblicas americanas, comienza a ser mirada como la posibilidad de la réplica del modelo de escuela pública que pudiera estar representado como uno de los lugares más claros por la propuesta de Sarmiento, uno de los padres más claros de la República Argentina, quien planteaba que la civilización llegaba por el Río de la Plata y la barbarie llegaba de la pampa. En la versión que se ha venido elaborando desde la educación popular en una perspectiva crítica y transformadora, se bebe como fuente primigenia de Simón Rodríguez, el maestro de Simón Bolívar, quien planteaba la necesidad de una educación popular que nos haga americanos y no europeos, y que marca una línea de algunos de los fundadores de las nacientes repúblicas, en donde estarían en esa línea José Artigas y José Martí. Estos elementos pueden rastrearse en la conformación de los sistemas nacionales de educación cuando las élites criollas trajeron a América al inglés Lancaster para organizar sus sistemas educativos. De igual manera, en esa historicidad pueden rastrearse otros hitos que desbordan el sentido de esta entrevista como las universidades populares, los proyectos de educación indígena, siendo el más reconocido el de Warisata, los proyectos educativos de sacerdotes obreros y misioneros en este continente, siendo uno de los más significativos el de Fe y Alegría. Asimismo, el movimiento de nueva cultura del nordeste brasilero, que seria el tronco freireano y lo que hemos llamado atrás los caminos de consolidación de la segunda mitad del siglo XX, paralelo a la emergencia de un pensamiento propio latinoamericano, que tiene entre sus principales hitos la teología de la liberación, el teatro del oprimido, la comunicación, la teoría de la dependencia, la psicología 
social, entre otros. El decantado conceptual nos permite hoy hablar de diez troncos históricos que dan forma a ese acumulado que, a manera de principios, se convierten hoy en un horizonte de acción de ella:

a. Su punto de partida es la realidad y la lectura crítica de ella, para reconocer los intereses presentes en el actuar y en la producción de los diferentes actores.

b. Implica una opción básica de transformación de las condiciones que producen la injusticia, la explotación, dominación y exclusión de la sociedad.

c. Exige una opción ético-política en, desde y para los intereses de los grupos excluidos y dominados, para la pervivencia de la madre tierra.

d. Construye el empoderamiento de excluidos y desiguales, y propicia su organización para transformar la actual sociedad en una más igualitaria y que reconozca las diferencias.

e. Construye mediaciones educativas con una propuesta pedagógica basada en procesos de negociación cultural, confrontación y diálogo de saberes.

f. Considera la cultura de los participantes como el escenario en el cual se dan las dinámicas de intraculturalidad, interculturalidad y transculturalidad de los diferentes grupos humanos.

g. Propicia procesos de autoafirmación y construcción de subjetividades críticas.

h. Se comprende como un proceso, un saber práctico-teórico que se construye desde las resistencias y la búsqueda de alternativas a las diferentes dinámicas de control en estas sociedades.

i. Genera procesos de producción de conocimientos, saberes y de vida con sentido para la emancipación humana y social.

j. Reconoce dimensiones diferentes en la producción de conocimientos y saberes, en coherencia con las particularidades de los actores y las luchas en las cuales se inscriben.

El lugar epistémico estaría caracterizado por lo que denominaríamos el "sur", no como lugar geográfico, ni antípoda de lo eurocéntrico, sino como una manera de darle lugar a lo diverso, y en ese sentido sería complementario en lo pluriverso de lo universal, recupera la unidad de la naturaleza y de lo humano desde el buen vivir, da expresión a las cosmogonías como una forma de visibilizar las identidades, encuentra en las nuevas formas de lo comunitario la manera de lo común para avanzar hacia las transformaciones y hace una lectura del poder más allá de lo económico y lo político. Su propuesta pedagógica construida en su larga tradición desde Simón Rodríguez, cuando enfrentó el lancasterianismo 
señalándolo como "aprender de memoria y repetir sin sentido" o en las experiencias de Warisata, por darle lugar a lo propio, o en Freire por dar lugar a la palabra del oprimido en una pedagogía liberadora. Hoy podemos decir que construye su propuesta basada en el diálogo de saberes que da forma a la intraculturalidad, que permite definir identidades a una confrontación de saberes que construye la interculturalidad, como la manera de darle lugar a lo diverso, a lo diferente, pero impugnando desigualdad y opresión y la negociación cultural que construye transculturalidad para poder estructurar los comunes que permiten las agendas para la práctica transformadora.

CIMEAC: Cuando pensamos la organización del sistema educativo formal en la realidad latinoamericana, identificamos una serie de influencias europeas en el marco de su fundamentación e implementación. Así es importante analizar el discurso de la emancipación y transformación social desde sujetos críticos y proactivos en los procesos de toma de decisiones propios del campo de la educación popular, así como desde su articulación con los procesos educativos pensados y diseminados en el contexto de la institución escolar. ¿Cómo implicar los sistemas oficiales con las cuestiones y discursos propios de la educación popular? ¿Cómo el programa ONDAS, dirigido por usted, identifica la relación entre los discursos oficiales y las perspectivas políticas de la educación popular?

Marco Raúl Mejía: Es necesario aclarar que en estos momentos no estoy ya en el Programa Ondas, estuve en la dirección de un equipo que tuvo como tarea el diseño de su propuesta metodológica denominada Investigación como Estrategia Pedagógica (IEP). Este es un buen ejemplo práctico de la manera cómo los elementos desarrollados en las preguntas anteriores toman forma en una propuesta metodológica. En ese sentido, si se consultan algunos de los videos existentes en YouTube y sus documentos, se puede ver son mayor sentido lo que se afirma en esta pregunta. Su fundamento es la pregunta por cómo se produce la desigualdad en el mundo del trabajo inmaterial y cómo afrontarla educativamente, lo cual nos llevó a construir una propuesta para niños, niñas y jóvenes basados en la manera cómo ellos y ellas se hacían humanos. Por eso, su punto de partida son las capacidades (Nussbaum, Sen y otros) y no las competencias. Con ello se disputaba el proyecto transnacionalizado que corría en educación. Planteado el asunto así, nos preguntamos de qué manera, con un ejercicio investigativo desde las preguntas que se hacen las culturas infantiles sobre sus contextos, se pueden generar problemas investigativos que les van a permitir generar habilidades blandas y desarrollar imaginarios de innovación para la vida, a través de proyectos de investigación desde las más diversas áreas del conocimiento. A nivel investigativo, se asume la libertad epistemológica en el sentido de diversas maneras de entrar al conocimiento y el reconocer los saberes y la sabiduría como procesos emergentes para ser conocidos, lo cual va a implicar también diversidad metodológica, que es acompañada por maestras y maestros para la transformación de su práctica 
pedagógica y la generación al recorrer el camino de la emergencia de un pensamiento crítico que tiene consecuencias sobre sus contextos. El trabajo que se desarrolla da forma a distintos procesos de aprendizaje que permiten, en el desarrollo de la experiencia, un trabajo colaborativo que produce comunidades de práctica, aprendizaje, saber, conocimiento, innovación y transformación, en un ejercicio de permanente debate y discusión que hacía visible que la pedagogía no es una receta ni un asunto técnico instrumental, sino que en la metodología se hacen presente las apuestas de sociedad, de ser humano y de construir sociedad en estos cambiantes tiempos. De igual manera, desechamos esa idea tan de los años 70 marcado por la influencia althusseriana de que el Estado es el gran aparato de control del capital y que estar a su interior era ser preso de la dominación, y se fue construyendo a su interior una idea de lo público como un espacio en disputa al cual concurren los diferentes actores de la sociedad por colocar sus concepciones en esos espacios, como una manera de ir construyendo lo popular con un sentido y un significado propio del poder que se intenta construir. Esto significó discutir fuerte con las posiciones más basistas y populistas de la educación popular, que planteaban la imposibilidad de hacerlo en el Estado y no en relación directa con los grupos marginados de la sociedad. También brotó allí el debate sobre hasta qué nivel era necesaria una elaboraión académica que disputara en tales espacios, pero para muchos, era entrar por vía de la investigación en una ciencia al servicio del capitalismo, al cual se colocaban los niños, las niñas y los jóvenes que estaban en el Programa. Esta experiencia inició procesos de endogenización en algunos lugares como Bolivia, Perú, y México. Este debate es revivido cuando debemos salir del programa, que en su momento tenía 22,000 maestras y maestros y un millón de niñas, niños y jóvenes. Al llegar una nueva dirección colocada luego de una década de trabajo, ellos van a plantear en algunos casos, que la IEP no existe o es una sobrepolitización de un proyecto, y reordenan la propuesta hacia el STEM, lo cual les ha generado un debate interno de los grupos regionales que se acompañaban.

CIMEAC: ¿Qué aspectos fundamentales deben ser considerados en el proceso de formación de educadores populares? Considerando los procesos de formación inicial docente en Brasil y en Colombia se nota aspectos que no son considerados por las instituciones formadoras y que son fundamentales en un proyecto de educación emancipador y transformador. Así, ¿cómo pensar procesos y proyectos para la formación de colectivos de educadores populares?

Marco Raúl Mejía: Estamos hablando en esta pregunta de uno de los asuntos más críticos en la reconfiguración del saber escolar de la modernidad, en donde todas las instituciones de saber encargadas de estos asuntos, han entrado en profundos replanteamientos derivados de los cambios de época y las nuevas maneras cómo la organización de la sociedad requiere nuevas habilidades. De 
igual manera, el hecho de que la educación en el último período de tiempo haya estado aprisionada por una industria del conocimiento, que ha sido el soporte fundamental del STEM, el cual ha sido instaurado desde los organismos multilaterales. Una de sus consecuencias es que, en algunos lugares, las facultades de educación están siendo reorganizadas y trasladadas a las ingenierías. Un elemento central que ha acompañado las contrarreformas educativas asesorado por la banca multilateral, es la manera cómo se instaura la despedagogización, en cuanto se toma un discurso sobre el conocimiento haciéndolo técnico objetivo, el cual debe ser apropiado en la versión que ellos han organizado de estándares y competencias, y desde un entendimiento de él que corresponde al modo 1 de la ciencia, donde es un currículo de tipo lineal y algorítmico. Las manifestaciones más claras de esa despedagogización son la desvalorización del papel del maestro, la reducción de la pedagogía a mínimos didácticos, la pauperización de la vida material y simbólica de los maestros y maestras, y el ataque a las formas de organización sindical. Allí la educación popular ha entrado en un debate práctico-teórico, en cuanto ha venido alimentando una serie de experiencias que se dan a lo largo y ancho del continente, no solo en procesos de educación formal, sino en los distintos ámbitos de educación, colocándose claramente como parte de disputa de esos sentidos, mostrando que la educación y la pedagogía no son solo saberes técnicos objetivos. Para ello, ha venido reelaborando la idea de los aprendizajes como esos espacios en los cuales se juegan los sentidos de la educación, y para ello ha construido la especificidad de su tradición, aprendizajes situados, colaborativos problematizadores, y de indagación crítica. En esa medida, desde la práctica de los participantes ha venido generando dinámicas de formación in situ, que tienen su fortaleza en unas dinámicas integrales de autoformación, formación colaborativa, producción de saber y conocimiento, y dinámicas de apropiación, en las cuales quienes están en ellas, pueden replicarlas y generar procesos de aprendizajes de pares, haciendo del hecho educativo y pedagógico un mundo en el cual se opera a través de dispositivos de saber y poder que se ponen en juego en el ejercicio metodológico cotidiano. Esto exige la claridad de la orientación pedagógica con la cual se trabaja. En distintos ámbitos esto ha ido dando forma a múltiples expresiones de movimientos pedagógicos, que van haciendo de estos procesos y dinámicas unos nuevos movimientos sociales con especificidad en los asuntos que tienen que ver con la manera cómo se construye lo educativo en este tiempo. La educación popular allí, al entrar en este debate desde las prácticas específicas, participa con propuestas en la reelaboración de las dinámicas de formación.

CIMEAC: La organización social CIMEAC (Centro de Investigaciones de Metodologías Alternativas Conexión), en una de sus frentes de trabajo, actúa con jóvenes urbanos con alta vulnerabilidad socioeconómica desde una 
perspectiva de la educación popular. Así, la organización curricular prevé el desarrollo de "habilidades para la vida", conforme su libro La sistematización. En esta obra hay una tesis de que la sistematización de la propia práctica es condición para la producción de conocimiento a partir de la experiencia. ¿Cómo movilizar a un grupo de educadores populares, muchas veces enfocados en sus experiencias urgentes y emergentes de los contextos en que actúan, a una postura investigativa para investigar su propia práctica?

Marco Raúl Mejía: Creo que éste es uno de los lugares más importantes que hace visible ese carácter de acumulado en disputa que se coloca en la sociedad para poner en juego el acumulado de la educación popular y no permite disociar en ella lo teórico conceptual de lo práctico transformador, mostrando que ellas son una unidad que debe trabajarse con igual rigor para poder disputar en los distintos niveles populares, sociales, académicos en los cuales se juegan los sentidos de la educación en la sociedad de hoy. La sistematización emerge como una forma de investigar las prácticas y allí habría que afirmar que en alguna medida la investigación es una forma de acercarse a la realidad desde distintos lugares epistémicos. Por eso pudiéramos afirmar que en occidente hemos tenido cuatro aproximaciones a la realidad: la teórica, la experimental, la de la acción humana, la autoobservante y, desde nuestra mirada, la sistematización aparece como esa quinta manera de acercarse a la realidad, que es la práctica reflexionada. Ello, posibilitado por esas emergencias de los pensamientos propios en nuestro contexto latinoamericano señalada en alguna de las preguntas anteriores. Cuando nos referimos a esta quinta manera de acercarse a la realidad, va a significar que la práctica reflexionada permite la emergencia de los múltiples aspectos con los cuales está constituido lo diverso, lo diferente, haciendo explícito la síntesis de sus múltiples componentes. Es ahí donde eso propio, que ha sido nombrado como sur, como resistencia-reexistencia, como cosmogonías, adquiere especificidad en la voz de los actores que le dan sentido a lo que hace, convirtiéndolo en saber y en conocimiento. Este asunto es central al proyecto de poder de la educación popular, en cuanto le permite a los actores de práctica desmitificar la idea de investigación, saliendo de la mirada que la refiere a un marco conceptual previo en el cual se inscribe su práctica, y ahí la sistematización le va a permitir colocar un escenario en donde los actores de la práctica no solo la nombran, sino que la colocan en escenarios de disputa de poder con otros marcos conceptuales, generando dinámicas de empoderamiento, en cuanto hace visible cómo la práctica y los actores de ella producen saber y conocimiento. A nivel de política del conocimiento, abre un camino que busca romper la separación entre trabajo manual y trabajo intelectual y entre teoría y práctica, tan propios del control capitalista de este tiempo. Para ello, ha generado propuestas metodológicas en el día a día de los actores de práctica para que puedan ir haciendo las elaboraciones desde los referentes de su quehacer. Por ello, hoy podemos hablar de la existencia de diferentes concepciones de sistematización, y en el sentido de los grupos, de la pregunta 
que se hace, invito a visitar la experiencia del grupo de educación popular Combos de Colombia, el cual desde niños y niñas en condición de calle muestra toda una elaboración propia de la sistematización.

CIMEAC: La colonización de los saberes, el eurocentrismo y la globalización capitalista se colocan en su libro Educación popular en el siglo XXI como elementos fundamentales de la modernidad y que configuran el pensamiento hegemónico. El conocimiento científico emerge como el conocimiento que valida esa hegemonía y que representa una fuerza motriz de las relaciones de poder características de ese período histórico. Así, usted anuncia que la negociación cultural desde una perspectiva ecológica de los saberes, en las palabras de Boaventura de Sousa Santos, pueden ser un camino para la superación del pensamiento hegemónico. ¿Cómo pensar el abordaje de conceptos y teorías científicas, con epistemologías propias, pero que pueden dialogar con algunos puntos de otras epistemologías que son tradicionalmente presentes en las comunidades en que nosotros estamos insertados?

Marco Raúl Mejía: Es necesario volver a afirmar que el capitalismo busca consolidar su control y hegemonía con la tercera homogeneización, la de la educación. Ello exige de los educadores populares de este tiempo, colocarnos críticamente sobre ellas y mostrar cómo es posible. En ese sentido, hay que recuperar el llamado de Boaventura de Sousa Santos sobre la ecología de saberes, lo cual nos habla de diferentes temporalidades, identidades, escalas, producciones, para mostrar cómo sobre esa homogeneización se tejen otras narrativas que, a la vez que impugnan muestran otras maneras de concebir la vida para estos tiempos, desde otros lugares. Por ello, la educación popular ha hecho un tránsito en su constitución de los movimientos ocupándose de los derechos como una forma de acceder a la constitución de la sociedad liberal, de las resistencias como la manera a través de la cual impugnamos el control y sus dinámicas, y las reexistencias que han hecho visible que tenemos esos otros múltiples lugares desde los cuales construimos nuestras identidades forjadas en esos ejercicios de intra e interculturalidad, para dotarnos de una mirada que nos da otra manera de habitar los territorios. Allí emerge ese sur, que no es solo geográfico, sino como un lugar de identidad y confrontación y que comienza a enunciarse con unas narrativas propias, en donde toma expresión lo diverso, lo diferente, lo integral y lo desigual. Esa perspectiva está orientada por el principio de complemetariedad. Por ello el sur no está enfrentado al norte ni es tampoco un lugar geográfico. Y esta es la dificultad para entenderlo, para el pensamiento dicotómico occidental, y va a ser la capacidad de enuciarse con el otro para hacer explícita la diferencia y la diversidad. Es así como a la homogeneización biótica, muy actual con los procesos de la megaminería, se plantea un mundo integral, en donde el buen vivir y el vivir bien nos plantean la existencia de un mundo biocéntrico, donde los derechos no son solo de lo humano, sino también de la madre tierra, y ello implica una corresponsabilidad, por ejemplo, de hacer posible 
en el mundo de la vida otra matriz energética. A la homogeneización cultural del eurocentrismo y de la industria cultural, se ha ido mostrando que a esa monocultura del saber y el conocimiento, existen otras maneras de narrar, otros métodos, que explican desde otros sentidos e identidades y desde cosmogonías negadas que hoy comienzan a ser visibilizadas, mostrándonos que hay otras epistemologías, otras formas del conocimiento, con otros relatos, un pensamiento que rompe la asfixia de una única mirada, y da forma a lo singular y a lo diverso sin caer en particularismo. En ese sentido, se está regido por la complementariedad y no por lo nuevo otro como absoluto. Por ello, no es un saber de la periferia, es activo, está sobre los territorios, en ocasiones más visible o menos, de acuerdo a las condiciones que permiten su emergencia, mostrándonos que es activo, que muchos desde el silencio viven orientados por sus enunciados cuando se profundice nos muestran nuevas formas de una acción ética y otras maneras de constituir las narrativas en los territorios. El sur como proyecto está en el norte, en grupos y personas que deciden cambiar la vida y construir un mundo donde caben muchos mundos, abierto a la diversidad y a otras formas de la comunidad en estos tiempos, atravesados por lo que Jesús Martín-Barbero llamó la "comunidad mosaico". Frente a la homogeneización educativa en marcha, la propuesta de educación popular reorganiza sus apuestas desde un proyecto que afirma la integralidad de lo humano a partir de las capacidades; de igual manera, unas pedagogías para tramitar los conflictos desde su propuesta metodológica del diálogo, la confrontación de saberes y la negociación cultural. Una anécdota para ilustrar esto, vivida en Brasil, en un debate sobre la inclusión a la universidad de los afros y de los indígenas, y decíamos, el derecho ha permitido una inclusión de sus cuerpos a la universidad, pero al ir a un proyecto eurocéntrico van a ser "blanqueados", en cuanto sus epistemologías, sus narrativas, sus cosmogonías, sus métodos, se han quedado en sus comunidades y son negados como saber por estas instituciones fundadas en el eurocentrismo.

CIMEAC: Considerando la idea de una escuela con prácticas interculturales que no desconsideren las asimetrías sociales y económicas históricamente construidas, ¿cuáles serían los grandes impactos de las políticas públicas como una base nacional curricular común o la perspectiva de una "escuela sin partido" en el contexto brasileño? ¿Cómo los aspectos políticos han influido en las propuestas de educación popular en Colombia?

Marco Raúl Mejía: Si bien en las respuestas anteriores hay elementos para responder esta última pregunta, decantemos y profundicemos algunos de ellos. El proyecto educativo del STEM es la resultante del informe "Una nación en riesgo" de comienzos de la década de los 80 del siglo pasado en el mundo norteamericano, construido bajo la pregunta: ¿cómo dar respuesta desde la educación a la tercera revolución industrial? Curiosamente fue la misma 
pregunta que se hizo Finlandia. El control norteamericano del mundo orientó qué se necesita saber en la globalización capitalista y neoliberal, y ese proyecto se transnaconaliza a través del Banco Mundial, la OCDE (quien realizará las próximas pruebas PISA diseñadas por el grupo Pearson, haciendo real la industria del conocimiento). Si vemos el contenido esa comisión de calidad de la educación de los Estados Unidos que orienta el STEM a la educación, encontramos que su discurso es positivista, encontramos que la idea de ciencia es de un pensamiento cerrado, del modo 1 de ella y sus resultados se miden con la inserción laboral al mundo del trabajo. Esto se hace pedagógicamente en un modelo instruccionista de aprender y aplicar, lo que implica una propuesta de evaluación prescriptiva. Este modelo ha sido cuestionado, los coreanos le agregan la $\mathrm{A}$ de arte, como un elemento clave para los diseños virtuales y de realidad aumentada. En los mismos Estados Unidos el Instituto Nacional de Ciencia, le plantea a la Secretaría Nacional de Educación, colocarle la $\mathrm{H}$ de "humanities". Un acercamiento primero a esto es la invitación a mirar los textos de la Sra. Diana Ravitch en internet. Curiosamente la propuesta de despolitización a la que se alude en la pregunta fue asumida por el gobierno de Temer en Brasil, en las directivas educativas enviadas a los centros escolares posteriores al "golpe de estado" del senado. Por ello podemos afirmar que nunca fue tan política la educación como en estos tiempos, en cuanto se ha convertido en un espacio en disputa, el cual intenta dirigir los asuntos de la ciencia y el conocimiento y la manera cómo se produce la tensión y el poder en educación. Allí la educación popular acaba de construir su apuesta para marcar con forma propia en el siglo XXI, su apuesta para construir y disputar en todas las esferas de la educación, haciendo de la realidad glocal ese nuevo escenario en el cual construye ciudadanos del mundo, pero hijos de la aldea, sin caer en utopismos pedagógicos, recordando con Freire que la educación sola no cambia la sociedad, pero sí cambia las personas que van a transformar la sociedad. Hoy, en América Latina, son prolíficas las propuestas que desde la educación popular siguen en política educativa en los niveles micro, meso y macro. Mencionemos algunas de ellas: la ley 070 Avelino Siñani y Elizardo Pérez de Bolivia; los bachilleratos populares argentinos; los proyectos de educación propia de indígenas y afros; y las expresiones de universidades populares y de educación popular, así como maestrías y pregrados que forman en su propuesta pedagógica; el proyecto internacional de educación popular de Fe y Alegría; los proyectos educativos y pedagógicos alternativos (PEPAs) en Colombia; la discusión chilena que ha implicado cambios en el gremio; los currículos alternativos mexicanos en Oaxaca PETEO, y BECEM en Michoacán. 


\section{ENTREVISTADORES}

\section{Danilo Seithi Kato}

Universidade Federal do Triângulo Mineiro (UFTM)

\section{Marisol Uribe Pérez}

Universidad Districtal Francisco José de Caldas (DIE - UD)

Recebido em: 16/11/2017 Aprovado em: 17/12/2017

\section{Felipe Ziotti Narita}

Universidad de São Paulo (USP) Universidad del Estado de São Paulo (Unesp) 


\section{A GLOBALIZAÇÃO CAPITALISTA E O LUGAR EPITÊMICO DA EDUCAÇÃO POPULAR NA AMÉRICA LATINA

\author{
Entrevista com Marco Raúl Mejía
}

MARCO RAÚL MEJÍA é licenciado em Filosofia e Letras pela Pontifícia Universidade Javeriana de Bogotá (Colômbia) e doutor pelo Projeto Interdisciplinar de Investigações Educacionais no Chile (PIIE). Autor de importantes livros e textos sobre educação popular na América Latina, como Globalizaciones y educaciones, Educación popular en el siglo XXI e Sistematización. Além da produção teórica, Marco Raúl Mejía também atua como educador popular nos projetos Planeta Paz e Expedición Pedagógica Nacional de Colombia.

\section{$\star * *$}

CIMEAC: Os projetos de educação popular na América Latino têm sido fundamentais para a consolidação da sociedade civil a partir dos anos 1980 e 1990. Como você analisa esse processo tendo em conta a democratização política das sociedades latino-americanas naquela conjuntura? É possível dizer que a educação popular desempenhou uma função importante para a construção democrática no continente?

Marco Raúl Mejía: Acho que este é um dos pontos mais importantes na consolidação da educação popular na América Latina, mas igualmente representou um dos momentos mais paradoxais, porque após esse período de fim das ditaduras muitas das pessoas que haviam trabalhado com educação popular e algumas agências de cooperação que haviam ajudado no financiamento afirmaram que era o fim da educação popular, uma vez que sua vigência estava atrelada ao processo de consolidação das democracias. Esse momento abre um grande debate sobre qual é o lugar, nas democracias que eram inauguradas, da proposta da educação popular, de modo que neste período aparece um grande debate sobre a meneria pela qual a transição deveria ser aproveitada para organizar uma fundamentação da educação popular capaz de colocá-la em face das novas realiades de uma globalização capitalista e neoliberal em curso. É um momento em que, apesar das posicições sobre o fim da educação popular, aparecem propostas como a refundamentação, a reconfiguração e a rearticulação aos projetos populares, além de outros termos que tentavam dar conta de como viver essa transformação. Esse momento histórico abre um debate profundo sobre os conteúdos da educação popular, sua ligação ao projeto freireano ou ao projeto marxista de transformação das estruturas, tendo início os primeiros balanços sobre o que havia sido a educação popular e sua articulação com os processos revolucionários na América Central, 
além da introdução de discussões sobre sua pedagogia, sua ética, suas relações com o marxismo clássico, com o início de um período profundo de elaboração que pode ser visto nos debates gerados na revista La Piragua (CEAAL) e nos processos de movimentos sociais que acompanharam essa transição para a democracia. Poderíamos afirmar que essas resistências contra a ditadura para refundar a democracia foram centrais nas discussões em educação popular, sendo este um período difícil em função das desqualificações dirigidas entre as diferentes posições, ao passo que os discursos sobre o reformismo, a socialdemocracia, a revolução, o intelectualismo e o populismo impregnaram o debate sobre educação popular. Esse debate permitiu decantar uma educação popular que, a partir de várias concepções e posições, acompanhou o surgimento ao redor do continente do que seria o ciclo de governos progressistas (Venezuela, Equador, Bolívia, Brasil, Chile, Uruguai, Argentina), tendo como correlato o fato de que muitos movimentos apoiaram esses processos, gerando uma dinâmica na qual muitos dos educadores populares ocuparam postos governamentais, constituindo um novo âmbito de atuação dos educadores populares que ainda não havia sido ocupado nos desenvolvimentos da educação popular na segunda metade do século XX. Surgiu toda uma discussão sobre a maneira como esses governos cooptaram os movimentos sociais e muitos deles foram subsumidos em suas plataformas programáticas. Em outros lugares surgiu uma discussão sobre a maneira por meio da qual era necessário construir o político do social, permitindo diferenciá-lo do político-partidário. Esses debates permitiram uma elaboração que avançou sobre a maneira pela qual a política também começava a ter particularidades a partir do contexto latino-americano, em registros diferentes do que seria o pensamento clássico (ortodoxo) do marxismo como pensamento crítico por excelência do Ocidente. Esse debate não está concluído, mas tem sido de uma vitalidade que se tornou uma seiva da educação popular, ao passo que permitiu diferenciar e decantar sua proposta como uma proposta para toda a sociedade, obrigando a uma reorganização do pensamento não apenas à luz dos fenômenos da terceira e da quarta revolução produtiva, mas igualmente à luz das crises dos governos progressistas que colocaram novos assuntos centrais a um exercício que o padre Cardenal, da Niacarágua, chamou de "o ético como exigência da política", que consistia em dizer que não bastava mudar a sociedade ou ter o sonho de assim fazer se não mudássemos a vida e a maneira pela qual os ideais desse projeto eram encarnados no cotidiano e no fazer das pessoas, dos movimentos e das instituições.

CIMEAC: A reconfiguração da sociedade de classes, no contexto do capitalismo cognitivo e da ascensão do imaterial, tem produzido mudanças importantes no saber e em suas formas de circulação e apropriação. Como você analisa a educação popular à luz desse processo social mais amplo? 
Marco Raúl Mejía: Como qualquer atividade humana da nossa época, a educação popular é afetada por um mundo que, em seus últimos 40 anos, vivenciou duas revoluções produtivas (a da microeletrônica e a do trabalho imaterial e da inteligência artificial), quando foram necessários 300 anos para as duas primeiras (a do vapor e a da eletricidade). Nessa perspectiva, a educação popular não apenas está direcionada a pensar o mundo local, mas a emergência de um mundo glocal caracterizado por profundas transformações em que os assuntos dos quais ela se ocupa são transformados à luz de um novo fenômeno, no qual a ciência é convertida em força produtiva fundamental com as consequências da necessidade de reelaboração dessa teoria sobre o capital e a maneira como ele se desenvolveu nas particularidades de nossa formação social. A particularidade deste tempo, conforme a pergunta, é que essa ciência, ao ser convertida em força produtiva fundamental pela espetacularização das mudanças tecnológicas, implica que, por alguns momentos, esqueçamos que ela é resultante do trabalho humano que Marx havia chamado de "força científica objetivada", exigindo uma releitura desse pensamento crítico para trazê-lo às nossas realidades e assim fazer um balanço sobre a maneira pela qual o capital se apropria dessa ciência e a coloca a seu serviço. Por isso, uma releitura dos Grundrisse será muito importante para o pensamento crítico deste tempo, tentando explicar os novos comportamentos das classes em um contexto em que as novas forças sociais produtivas são produzidas como ciência, mas igualmente em um contexto de organização da praxis social cotidiana. Este tempo é maravilhoso para a educação popular, pois ela está em um momento de consolidação em que é preciso que ela se entenda junto aos fenômenos do capital global e à maneira pela qual, em sua formação social, adquire concretude essa realidade a partir de nossas particularidades, como já nos havia ensinado Mariátegui quando falava da sociedade indo-americana, o que the valeu uma reprimenda do Komintern na década de 1930, ou conforme pensadores como 0 boliviano Zabaleta ao falar das "formações sociais heterogéneas", mostrando a convivência dessas múltiplas formas do capital que são específicas e particulares na singularidade de nossa formação social. Essa consolidação da educação popular como um projeto educativo para toda a sociedade e todas as formas de educação permite decantar nessa leitura crítica um novo horizonte teórico, lembrando como o capitalismo ocidental tem sido constituído a partir de homogeneizações que constroem um único relato do mundo, tanto em sua versão liberal ou na versão mais crítica e emancipadora, dando forma a explicações universais que começam a ser discernidas em meio às novas condições do mundo e às particularidades de nossos contextos. A primeira homogeneização sobre a qual o capital é produzido é a biótica, que, ao construir o predomínio do humano sobre a natureza e um sistema de objetivação da natureza, produz um antropocentrismo que permite uma visão de exterioridade da natureza. No horizonte destes tempos, no pensamento latino-americano tem surgido com força própria o olhar sobre o Bem Viver / Viver Bem, no qual existe 
a ênfase sobre um mundo integral e uma unidade a ser recuperada em qualquer projeto que alguém tenha a pretensão de construir. A segunda homogeneização, a cultural, permitiu a construção de um relato da modernidade centrado na ideia de progresso, com um conhecimento universal de base eurocêntrica e norteamericana, constituído em um relato único para a explicação do mundo, permitindo a organização do mundo em desenvolvimento e subdesenvolvimento, moderno e pré-moderno, capitalista e pré-capitalista. A partir dos setores críticos e da educação popular, tem ficado visível a maneira como emerge um Sul, tornando visível a diversidade, a diferença, em um mundo onde as desigualdades são construídas por sua negação e pela incapacidade de construção de mundos pluriversos. A tereira homogeneização em curso é educativa e pretende fechar o ciclo de um mundo organizado através de padrões universais estabelecidos a partir do STEM (acrônimo de Science, Technology, Engineering, Mathematics ou Ciência, Tecnologia, Engenharia, Matemática, conforme suas siglas em inglês), para o qual são formados padrões e competências de referência universal para viver nesse mundo produtivo. A educação popular, à medida que consolida seu acúmulo, desenvolve propostas que permitem recuperar a diversidade, trabalhando um projeto integral do humano a partir das capacidades e das habilidades, desenvolvendo metodologias que tornam possível a expressão dessa diversidade.

CIMEAC: Em um artigo publicado em 2007 na revista Pasos, você define a educação popular como uma prática de "empoderamento que permita aos grupos segregados e desiguais construir um projeto de sociedade". Na América Latina, à luz da modernização capitalista dos últimos 150 anos, indicadores crônicos de desigualdade e assimetrias sociais constituem contextos de exclusão e deterioração do social. Há um conjunto estrutural de problemas no horizonte da educação popular latino-americana capaz de torná-la um campo unificado de práticas e pesquisas?

Marco Raúl Mejía: Sendo coerente com as respostas às duas questões anteriores, podemos afirmar que hoje a educação popular é uma proposta educativa para toda a sociedade em seus diferentes âmbitos, com um acúmulo que permite construir um campo prático-teórico que, pela forma como foi desenvolvido, está em constituição permanente para dar resposta aos tempos atuais. Nesse sentido, poderíamos dizer que esse acúmulo dota a educação popular de uma história, uma conceptualização decantada, um lugar epistêmico, uma proposta pedagógica e novas metodologias de pesquisa. Sua história, à medida que começa a ser aprofundada, é confundida com a maneira pela qual o projeto da Revolução Francesa tratou a educação popular como pública, possibilitando acesso a quem não tivera acesso ao conhecimento e ao saber como fator básico de democratização. Nesse sentido, essa versão de educação popular que chega às nascentes repúblicas americanas começa a ser olhada 
como a possibilidade da réplica do modelo de escola pública que é representado de forma clara pela proposta de Sarmiento, um dos pais da República Argentina, que acreditava que a civilização chegava pelo Rio da Prata e a barbárie pelos pampas. Na versão de uma educação popular em uma perspectiva crítica e transformadora, a fonte primeira é Simón Rodríguez, o professor de Simón Bolívar, defensor de uma educação popular que nos fizesse americanos, não europeus, marcando uma linha entre alguns dos fundadores das nascentes repúblicas como José Artigas e José Martí. Esses elementos podem ser rastreados no ordenamento dos sistemas nacionais de educação quando as elites criolas trouxeram o inglês Lancaster para a América a fim de organizar os sistemas educacionais. Da mesma maneira, nessa historicidade é possível rastrear outros pontos que vão além do sentido desta entrevista, como as universidades populares, os projetos de educação indígena (sendo mais conhecido o de Warisata), os projetos educacionais de padres trabalhadores e missionários no continente (sendo um dos mais significativos o Fé e Alegria). Igualmente, o movimento da nova cultura do nordeste brasileiro, parte do tronco freireano e do que antes chamamos de caminhos de consolidação da segunda metade do século $X X$, paralelamente à emergência de um pensamento próprio latino-americano que tem entre seus principais marcos a teologia da libertação, o teatro do oprimido, a comunicação, a teoria da dependência, a psicologia social, entre outros. A decantação conceitual permite que hoje falemos de dez troncos históricos que conferem forma a esse acúmulo que, como uma espécie de princípios, são convertidos hoje em um horizonte de ação:

a. Seu ponto de partida é a realidade e a leitura crítica dessa realidade a fim de reconhecer os interesses presentes na atuação e na produção dos diferentes atores.

b. Implica uma opção básica de transformação das condições que produzem a injustiça, a exploração, a dominação e a exclusão da sociedade.

c. Exige uma opção ético-política nos, a partir e para os interesses dos grupos excluídos e dominados, para a sobrevivência da mãe Terra.

d. Constrói o empodamento de excluídos e desiguais e propicia sua organização para transformar a sociedade atual em uma sociedade mais igualitária e capaz de reconhecer as diferenças.

e. Constrói mediações educativas com uma proposta pedagógica baseada em processos de negociação cultural, confrontação e diálogo de saberes.

f. Considera a cultura dos participantes como o cenário no qual ocorrem as dinâmicas de intraculturalidade, interculturalidade e transculturalidade dos diferentes grupos humanos.

g. Favorece processos de autoafirmação e construção de subjetividades críticas. 
h. É compreendida como um processo, um saber prático-teórico que é construído a partir das resistências e da busca de alternativas às diferentes dinâmicas de controle nessas sociedades.

i. Gera processos de produção de conhecimentos, saberes e de vida no sentido da emancipação humana e social.

j. Reconhece dimensões diferentes na produção de conhecimentos e saberes, em coerência com as particularidades dos atores e das lutas nas quais estão inscritos.

O lugar epistêmico estaria caracterizado pelo que denominaríamos o "sul", não como lugar geográfico nem antípoda do eurocêntrico, mas como uma maneira de dar lugar ao diverso e, nesse sentido, seria complementar ao pluriverso do universal, pois recupera a unidade da natureza e do humano a partir do bem viver, dá expressão às cosmogonias como uma forma de tornar visível as identidades, encontra em novas formas do comunitário a maneira do comum para avançar no sentido de transformações e faz uma leitura do poder para além do econômicos e do político. Sua proposta pedagógica construída na larga tradição desde Simón Rodríguez, quando enfrentou o lancasterianismo, entendendo-o como um "aprender pela memória e um repetir sem sentido", ou nas experiências de Warisata, para dar lugar ao próprio, ou em Freire para dar lugar à palavra do oprimido em uma pedagogia libertadora. Hoje podemos dizer que a educação popular constrói sua proposta baseada no diálogo de saberes que dá forma à intraculturalidade, permitindo a definição de identidades em uma confrontação de saberes que constrói a interculturalidade, como a maneira de dar lugar ao diverso, ao diferente (mas condenando desigualdade e opressão), além da negociação cultural que constrói transculturalidade para poder estruturar os comuns que permitem as agendas para a prática transformadora.

CIMEAC: Quando pensamos sobre a organização do sistema educacional formal na América Latina, identificamos uma série de influências europeias nos marcos de sua fundamentação e implementação. Assim, é importante analisar o discurso de emancipação e transformação social a partir de sujeitos críticos e proativos nos processos de tomada de decisão próprios do campo da educação popular, bem como a partir de sua articulação com os processos educativos pensados e disseminados no contexto da instituição escolar. Como envolver os sistemas oficiais com as questões e os discursos próprios da educação popular? Como o programa ONDAS, dirigido por você, identifica a relação entre os discursos oficiais e as perspectivas políticas da educação popular?

Marco Raúl Mejía: É preciso esclarecer que hoje não estou mais no Programa Ondas. Estive na direção de uma equipe que teve como tarefa o desenho de sua proposta metodológica denominada Pesquisa como Estratégia Pedagógica 
(IEP). Este é um bom exemplo prático da maneira pela qual os elementos desenvolvidos nas perguntas anteriores ganham forma em uma proposta metodológica. Nesse sentido, se vocês consultarem alguns vídeos no YouTube e seus documentos, poderão ver a questão trazida pela pergunta. Seu fundamento é a pergunta referente a como é produzida a desigualdade no mundo do trabalho imaterial e como é possível afrontá-la educacionalmente, tema que nos levou a construir uma proposta para crianças e jovens baseada na maneira como eles e elas se tornavam humanos. Por isso, o ponto de partida são as capacidades (Nussbaum, Sen e outros) e não as competências. Com isso, o projeto transnacionalizado de educação foi contestado. Colocado 0 assunto dessa forma, perguntamos de que maneira, com um exercício investigativo a partir das perguntas feitas pelas culturas infantis sobre seus contextos, podem ser gerados problemas investigativos que permitam gerar habilidades e desenvolver imaginários de inovação para a vida através de projetos de investigação a partir das mais diversas áreas do conhecimento. Em um plano investigativo, foi assumida a liberdade epistemológica no sentido de diversas maneiras de adentrar o conhecimento e reconhecer os saberes e a sabedoria como processos emergentes, implicando diversidade metodológica acompanhada por professoras e professores para a transformação de sua prática pedagógica ao recorrer ao caminho da emergência de um pensamento crítico que tem consequências sobre seus contextos. $O$ trabalho desenvolvido produz distintos processos de aprendizagem que permitem, no desenvolvimento da experiência, um trabalho colaborativo que produz comunidades de prática, aprendizagem, saber, conhecimento, inovação e transformação em um exercício de permanente debate e discussão que torna visível o fato de que a pedagogia não é uma receita nem um assunto técnico-instrumental, mas que na metodologia estão presentes as apostas de sociedade, de ser humano e de construção da sociedade nesses tempos de mudança. Da mesma maneira, descartamos a ideia típica dos anos 1970, marcada pela influência althusseriana, de que o Estado é o grande aparato de controle do capital e que estar em seu interior significa ser preso pela dominação, de modo que foi construída em seu interior uma ideia do público como um espaço em disputa no qual concorrem os diferentes atores da sociedade colocando suas concepções nesses espaços, como uma maneira de construir o popular com um sentido e um significado próprios do poder que se pretende construir. Isso significou uma discussão dura com as posições mais basistas e populistas da educação popular, que indicavam a impossibilidade de fazer isso no Estado em vez de fazê-lo em relação direta com os grupos marginalizados da sociedade. Também brotou ali o debate sobre até que ponto era necessária uma elaboração acadêmica que disputasse tais espaços, mas para muitos isso era entrar pela vía da investigação em uma ciência a serviço do capitalismo, ao qual estavam colocados as crianças e os jovens que estavam no programa. Essa experiência iniciou processos de endogeneização em alguns lugares como Bolívia, Peru e México. Esse debate 
foi revivido quando saímos do programa, que no momento tinha 22.000 professoras e professores e um milhão de crianças e jovens. Ao chegar uma nova direção colocada após uma década de trabalho, eles argumentaram, em alguns casos, que a IEP não existe ou é uma sobrepolitização de um projeto e reordenaram a proposta para o STEM, fato que gerou um debate interno nos grupos regionais.

CIMEAC: Quais aspectos fundamentais devem ser considerados no processo de formação de educadores populares? Considerando os processos de formação inicial docente no Brasil e na Colômbia, notamos aspectos que não são considerados pelas instituições formadoras, mas são fundamentais em um projeto de educação emancipador e transformador. Então, como pensar processos e projetos para a formação de coletivos de educadores populares?

Marco Raúl Mejía: Nesta pergunta, estamos falando de um dos assuntos mais críticos na reconfiguração do saber escolar da modernidade. Todas as instituições de saber encarregadas desses assuntos atravessaram profundas reorientações derivadas das mudanças de época e das novas maneiras pelas quais a organização da sociedade requer novas habilidades. De igual maneira, vale destacar o fato de que a educação nos últimos tempos tem sido aprisionada por uma indústria do conhecimento, sendo o suporte fundamental do STEM, que foi instaurado a partir dos organismos multilaterais. Uma das consequências é que, em alguns lugares, as faculdades de educação estão sendo reorganizadas e transpostas para as engenharias. Um elemento central que acompanhou as contrarreformas educacionais, assessorado pelo sistema bancário internacional [banca multilateral], é a maneira pela qual foi instaurada a despedagogização, ao passo que é adotado um discurso sobre o conhecimento que o torna técnico e objetivo, devendo ser apropriado na versão de padrões e competências e a partir de um entendimento que corresponda ao modo 1 da ciência com um currículo de tipo linear e algorítmico. As manifestações mais claras dessa despedagogização são a desvalorização do papel do professor, a redução da pedagogia e mínimos didáticos, a pauperização da vida material e simbólica dos professores e professoras e 0 ataque às formas de organização sindical. A educação popular entrou em um debate prático-teórico, alimentando uma série de experiências que ocorrem pelo continente, não apenas em processos de educação formal, mas em distintos âmbitos de educação, colocando-se claramente como parte de disputa desses sentidos, mostrando que a educação e a pedagogia não são saberes técnicos objetivos. Para tanto, a educação popular vem reelaborando a ideia das aprendizagens como os espaços onde estão colocados sentidos da educação, construindo a especificidade de sua tradição, as aprendizagens situadas, os colaborativos problematizadores e a indagação crítica. Assim, a partir da prática dos participantes, dinâmicas de formação in situ tem sido geradas, tendo sua fortaleza em dinâmicas integrais 
de autoformação, formação colaborativa, produção de saberes e conhecimento e dinâmicas de apropriação, nas quais os envolvidos podem replicar e gerar processos de aprendizagens por pares, tornando o fato educativo e pedagógico um mundo no qual é possível operar através de dispositivos de saber e poder colocados no exercício metodológico cotidiano. Isso exige clareza da orientação pedagógica com a qual se trabalha. Em diversos âmbitos, isso deu forma a múltiplas expressões de movimentos pedagógicos que tornam esses processos e dinâmicas novos movimentos sociais com especificidade em relação aos assuntos que tem a ver com a maneira pela qual o educativo é construído em nossa época. A educação popular, ao entrar nesse debate a partir de práticas específicas, participa com propostas na reelaboração das dinâmicas de formação.

CIMEAC: A organização social CIMEAC (Centro de Investigações de Metodologias Educacionais Alternativas Conexão), em uma de suas frentes de trabalho, atua com jovens urbanos em alta vulnerabilidade socioeconômica a partir de uma perspectiva da educação popular. A organização curricular prevê o desenvolvimento de "habilidades para a vida", conforme seu livro A sistematização. Nessa obra, há a tese de que a sistematização da própria prática é condição para a produção de conhecimento a partir da experiência. Como mobilizar um grupo de educadores populares, muitas vezes focados em suas experiências urgentes e emergentes dos contextos em que atuam, no sentido de uma postura investigativa para pesquisar sua própria prática?

Marco Raúl Mejía: Acho que esse é um dos lugares mais importantes através do qual fica visível esse caráter de acúmulo em disputa, estabelecido na sociedade, para colocar em jogo o acúmulo da educação popular e não permite dissociar o teórico-conceitual do prático-transformador, mostrando que essas duas dimensões são uma unidade que deve ser trabalhada com igual rigor para poder disputar nos distintos níveis populares, sociais e acadêmicos nos quais são jogados os sentidos da educação na sociedade contemporânea. A sistematização emerge como uma forma de investigar as práticas e aí devemos afirmar que, em alguma medida, a pesquisa é uma forma de se aproximar da realidade a partir de diferentes lugares epistêmicos. Por isso, poderíamos afirmar que no Ocidente temos visto quatro aproximações à realidade: a teórica, a experimental, a de ação humana e a auto-obervante. A partir de nosso ponto de vista, a sistematização surge como essa quinta maneira de uma aproximação com a realidade, constituindo a prática reflexionada. Isso foi possibilitado por essas emergências dos pensamentos próprios em nosso contexto latinoamericano, conforme indicamos nas questões anteriores. Quando fazemos referência a essa quinta maneira de aproximação com a realidade, isso significa que a prática reflexionada permite a emergência dos múltiplos aspectos por meio os quais está constituído o diverso, o diferente, tornando explícita a síntese de seus múltiplos componentes. É aí que o próprio sul, como resistência- 
reexistencia, como cosmogonias, adquire especificidade na voz dos atores, convertendo-o em saber e em conhecimento. Esse assunto é central ao projeto de poder da educação popular, na medida em que permite aos atores de prática desmistificar a ideia de pesquisa, saindo da perspectiva referida por um marco conceitual prévio no qual a prática é inscrita, e aí a sistematização permite estabelecer um cenário onde os atores da prática não apenas a nomeiam, mas colocam a perspectiva em cenários de disputa de poder com outros marcos conceituais gerando dinâmicas de empoderamento, ao passo que tornam visível como a prática e os atores produzem saber e conhecimento. Como política do conhecimento, isso abre um caminho que busca romper a separação entre trabalho manual e trabalho intelectual e entre teoria e prática, tão próprios do controle capitalista de nossa época. Para isso, foram criadas propostas metodológicas no cotidiano dos atores de prática para que eles possam fazer as elaborações a partir dos referentes de seu fazer. Por isso, hoje podemos falar da existência de diferentes concepções de sistematização e, quanto aos grupos da pergunta, convido vocês a visitarem a experiência do grupo de educação popular Combos, da Colômbia, que mostra toda uma elaboração própria da sistematização a partir de meninos e meninas em situação de rua.

CIMEAC: A colonização dos saberes, o eurocentrismo e a globalização capitalista aparecem em seu livro Educação popular no século XXI como elementos fundamentais da modernidade, pois configuram o pensamento hegemônico. O conhecimento científico emerge como conhecimento que valida essa hegemonia e que representa uma força-motriz das relações de poder características desse período histórico. Nesse sentido, você anuncia que a negociação cultural a partir de uma perspectiva ecológica dos saberes, nas palavras de Boaventura de Sousa Santos, pode ser um caminho para a superação do pensamento hegemônico. Como pensar a abordagem de conceitos e de teorias científicas com epistemologias próprias, mas que podem dialogar com alguns pontos de outras epistemologias tradicionalmente presentes nas comunidades em que nós estamos inseridos?

Marco Raúl Mejía: É preciso voltar a afirmar que o capitalismo busca consolidar seu controle e hegemonia com a terceira homogeneização, a da educação. Isso exige que os educadores populares se posicionem criticamente e mostrem como é possível. Nesse sentido, precisamos recuperar o chamado de Boaventura de Sousa Santos sobre a ecologia de saberes, falando de diferentes temporalidades, identidades, escalas e produções, para mostrar como, sobre essa homogeneização, são tecidas outras narrativas que, uma vez que contradizem, mostram outras maneiras de conceber a vida para nossos tempos e a partir de outros lugares. Por isso, a educação popular fez uma transição em sua constituição, ocupando-se dos direitos como uma forma de acessar a constituição da sociedade liberal, das resistências como a maneira através da qual contradizemos o controle e suas dinâmicas, e as reexistências que tornaram 
visível o fato de que temos esses múltiplos lugares a partir dos quais construímos nossas identidades forjadas nos exercícios de intra e interculturalidade, para adquirirmos um olhar que nos concede outra maneira de habitar os territórios. Aí emerge esse sul, que não é apenas geográfico, mas um lugar de identidade e confrontação que começa a ser enunciado com suas narrativas próprias, onde toma expressão o diverso, o diferente, o integral e o desigual. Essa perspectiva está orientada pelo princípio da complementaridade. Por isso, o sul não está enfrentando o norte, tampuco é um lugar geográfico. E essa é a dificuldade em entendê-lo para o ponto de vista dicotômico ocidental, de modo que a capacidade de enunciação com o outro será importante para tornar explícita a diferença e a diversidade. É assim que, da homogeneização biótica, muito atual com os processos da mega-mineração, um mundo integral é onde o bem viver e o viver bem colocam a existência de um mundo biocêntrico onde os direitos não são apenas do humano, mas da mãe Terra, e isso implica uma corresponsabilidade, por exemplo, de tornar possível no mundo da vida outra matriz energética. Sobre a homogeneização cultural do eurocentrismo e a indústria cultural, tem ficado evidente que em relação a essa monocultura do saber e do conhecimento existem outras maneiras de narrar, outros métodos que explicam a partir de outros sentidos e identidade e partir de cosmogonias negadas, que hoje começam a ser visíveis, mostrando-nos que há outras epistemologias, outras formas do conhecimento, com outros relatos, ou seja, um pensamento que rompe a asfixia de um único olhar, dando forma ao singular e ao diverso sem cair em particularismos. Nesse sentido, esse processo é regido pela complementaridade e não pelo novo outro como absoluto. Por isso, não se trata de um saber da periferia, pois é ativo e está sobre os territórios, mais ou menos visíveis em ocasiões, de acordo com as condições que permitem sua emergência, mostrando-nos que é ativo e que muitos, a partir do silêncio, vivem orientados por seus enunciados e, quando se aprofundam, mostram novas formas de uma ação ética e outras maneiras de construir as narrativas nos territórios. O sul, como projeto, está no norte, em grupos e pessoas que decidem mudar a vida e construir um mundo onde cabem muitos mundos, aberto à diversidade e a outras formas da comunidade de nossos tempos, atravessado pelo que Jesús Martín-Barbero chamou de "comunidade mosaico". Frente à homogeneização educacional em curso, a proposta da educação popular reorganiza suas apostas a partir de um projeto que afirma a integralidade do humano a partir das capacidades; da mesma maneira, afirma pedagogias que transacionam os conflitos a partir da proposta metodológica do diálogo, da confrontação de saberes e da negociação cultural. Uma anedota, vivida no Brasil, ilustra isso: em um debate sobre a inclusão de afro-descendentes e indígenas na universidade, dizíamos que o direito permitiu uma inclusão de seus corpos na universidade, mas, no caminho de um projeto eurocêntrico, eles serão "branqueados" ao passo que suas epistemologias, suas narrativas, suas 
cosmogonias e seus métodos ficam em suas comunidades e são negados como saber por essas instituições fundadas no eurocentrismo.

CIMEAC: Considerando a ideia de uma escola com práticas interculturais que não desconsideram as assimetrias sociais e econômicas historicamente construídas, quais seriam os grandes impactos de políticas públicas como uma base nacional curricular comum ou a perspectiva de uma "escola sem partido" no contexto brasileiro? Como os aspectos políticos interferem nas propostas de educação popular na Colômbia?

Marco Raúl Mejía: Ainda que nas perguntas anteriores haja elementos para responder a esta última questão, decantemos e aprofundemos alguns pontos. $O$ projeto educativo do STEM é o resultante do relatório "Uma nação em perigo", do começo da década de 1980, no mundo norte-americano, construído sob a pergunta: como dar uma resposta, a partir da educação, à terceira revolução industrial? Curiosamente, foi a mesma pergunta feita na Finlândia. O controle norte-americano do mundo orientou o que era preciso saber na globalização capitalista e neoliberal, de modo que esse projeto foi transnacionalizado através do Banco Mundial e da OCDE (instituição que realizará as próximas provas do PISA, desenhadas pelo grupo Pearson, tornando real a indústria do conhecimento). Analisando o conteúdo dessa comissão de qualidade da educação dos Estados Unidos que orienta o STEM para a educação, vemos que seu discurso é positivista, vemos que a ideia de ciência vem de um pensamento fechado, do modo 1, e seus resultados são medidos com a inserção trabalhista no mundo do trabalho. Isso é feito pedagogicamente em um modelo instrucional de aprender e aplicar, o que implica uma proposta de avaliação prescritiva. Esse modelo tem sido questionado. Os coreanos adicionam o A de arte como um elemento-chave para os desenhos virtuais e de realidade aumentada. Mesmo nos Estados Unidos, o Instituto Nacional de Ciência adiciona o H de "humanities". Para uma primeira abordagem, vejam os textos da senhora Diana Ravitch na internet. Curiosamente, a proposta de despolitização aludida pela pergunta foi assumida pelo governo de Temer no Brasil, nas diretivas educacionais enviadas aos centros escolares posteriores ao "golpe de Estado" do Senado. Por isso, devemos afirmar que nunca foi tão política a educação como nestes tempos, já que foi convertida em um espaço de disputa que tenta dirigir os assuntos da ciência e o conhecimento, bem como dirigir a maneira pela qual se produz a tensão e o poder em educação. Aí, a educação popular acaba de construir para marcar, com forma própria no século XXI, sua aposta para disputar em todas as esferas da educação, fazendo da realidade glocal esse novo cenário no qual são construídos cidadãos do mundo, mas filhos da aldeia, sem cair em utopismos pedagógicos, recordando com Freire que apenas a educação não muda a sociedade, mas muda as pessoas que vão transformar a sociedade. Hoje, na América Latina, são prolíficas as propostas que, a partir da educação popular, 
desenvolvem política educacional nos níveis micro, meso e macro. Para mencionar algumas delas: a lei 070 Avelino Siñani e Elizardo Pérez da Bolívia; os bachilleratos populares argentinos; os projetos de educação própria de indígenas e afro-descendentes; as expressões de universidades populares e de educação popular, bem como mestrados e graduações de suas propostas pedagógicas; o projeto internacional de educação popular Fé y Alegria; os projetos educacionais e pedagógicos alternativos (PEPAs) na Colômbia; a discussão chilena; os currículos alternativos mexicanos em Oaxaca PETEO e BECEM em Michoacán.

\section{ENTREVISTADORES}

\section{Danilo Seithi Kato}

Universidade Federal do Triângulo Mineiro (UFTM)

\section{Felipe Ziotti Narita}

Universidade de São Paulo (USP)

Universidade Estadual Paulista "Júlio de Mesquita Filho" (Unesp)

Marisol Uribe Pérez

Universidad Districtal Francisco José de Caldas (DIE - UD)

Recebido em: 16/11/2017 Aprovado em: 17/12/2017 